\title{
Kirchliche Erneuerung am Beispiel der Freien evangelischen Gemeinden
}

\author{
Andreas Heiser ${ }^{*}$
}

What does renewal mean in the context of the planting of the Free Evangelical Church in 1854? Heiser argues that the renewal draws upon a constructed ideal of the New Testament church. This ideal is used as an overall concept of renewal. In a setting of political and cultural change due to the industrial era combined with the movement of the Evangelical Brethren Society and influenced by the "Réviel" rises a model of a community with voluntary membership and congregational-Presbyterian structure. Some systematical views on the understanding of scripture, faith, baptism, Eucharist and ministry point to the still ongoing ecumenical changes of the movement.

Keywords: Reformatio, restitutio, renewal, Hermann Heinrich Grafe (1818-1869), Evangelical Brethren Society, scripture, faith, baptism, the Lord's Supper, ministry

\section{Einleitung}

Wenn man von Erneuerung spricht, ist es lohnend bei den Begriffen einzusetzen, die sich hinter den variablen Vorstellungen von Erneuerung verbergen. Der Gründer der Freien evangelischen Gemeinden, Hermann Heinrich Grafe (1818-1869), ging bei seiner kirchlichen Erneuerung 1854 davon aus, dass das von ihm etablierte ekklesiologische Modell dem apostolischen Ideal der Urkirche mehr entsprach als das aus der Reformation hervorgegangene und von ihm in der Elberfelder Reformierten Kirche vorgefundene Kirchenmodell des corpus permixtum ${ }^{1}$.

* Andreas Heiser, PhD, Professor für Kirchengeschichte an der Theologischen Hochschule Ewersbach, Rektor der Theologischen Hochschule Ewersbach. Adresse: Jahnstraße 49-53, 35716 Ewersbach; e-mail: heiser@th-ewersbach.de.

1 Das antike Christentum beantwortete die Frage, wer zur Kirche gehörte, mit der Feststellung, die empirische, irdische Kirche sei ein corpus permixtum, gemischt aus Erwählten und Verworfenen, aus Frommen und Sündern (Augustinus, De doctrina christiana 3,45 [Des heiligen Kirchenvaters Aurelius Augustinus ausgewählte praktische Schriften homiletischen und katechetischen Inhalts, aus dem Lateinischen übersetzt und mit Einleitungen versehen v. Sigisbert Mitterer, Bibliothek der Kirchenväter 49, München 1925, S. 146f.]). Belegt wird die Auffassung mit dem Gleichnis vom Unkraut unter dem Weizen (Mt 13,25-30) und dem Logion „Viele sind berufen, einige aber sind auserwählt.“ (Mt 20,16 var; 22,14) Auch die lutherischen Bekenntnisse lehren dieses Verständnis von Kirche (CA VIII: „cum in hac vita multi hypocritae et mali admixti sint" [Die Bekenntnisschriften der evangelisch-lutherischen Kirche, hg. im Gedenkjahr der Augsburgischen Konfession 1930, Göttingen ${ }^{9} 1982$, S. 62,4]); vgl. auch Apologie CA VII/VIII, 1-16 (ibidem, S. 233,41-237,38). 
Unter dem Begriff renovatio ist Erneuerung im Sinn von Rückkehr zu einem früheren implizit besseren Zustand gefasst. Hinter restitutio steckt Erneuerung im Sinn von Wiederherstellung eines ursprünglichen besseren Zustands. Nicht zuletzt deutet reformatio auf Erneuerung im Sinn von Verbesserung eines Zustands, ähnlich wie bei einer Reparatur ${ }^{2}$. Impliziert ist auch hier, dass der vorfindliche Zustand eine Verschlechterung gegenüber einem vorausgehenden Idealzustand darstellt. Allen drei Begriffen ist gemeinsam, dass sich die Erneuerung - anders als bei der Revolution, die einen Bruch mit der Vergangenheit bedeutet, oder bei der umfassenden Neukonstruktion - an einem bestimmten Ideal orientiert, das einen besseren als in der Gegenwart vorfindlichen Zustand ausmacht ${ }^{3}$.

Dabei wird die Erneuerungsbewegung der Freien evangelischen Gemeinden als renovatio oder reformatio zu beschreiben sein, da es ihr nicht im Sinn der restitutio um maßstabsgetreue Wiederherstellung eines ursprünglichen Idealzustands ging, sondern um ein Orientieren an einem unter den Bedingungen der gewandelten politischen, wirtschaftlichen, sozialen und religiösen Verhältnisse wahrgenommenen Idealzustand ${ }^{4}$. Von Erneuerung im Sinn

2 Ähnlich wollte auch Luther nur die Wiederherstellung des früheren Zustands einer durch die Zeit verdorbenen Kirchenform erreichen und die Christen zur Wahrheit und Eindeutigkeit zurückführen, aber keine neue Kirche gründen. Anders sah das der Ordensgeneral der Dominikaner Kardinal Cajetan, der bereits früh die grundstürzenden Folgen von Luthers theologischen Anfängen erahnte, als er sagte „hoc est novam ecclesiam construere“. Der Satz findet sich in dem 18. Tractat, den Cajetan mit De confessione betitelt und in fünf quaestiones aufgeteilt hat. Ziel des ganzen Abschnittes ist es, Luthers Lehre als Neuerung zu brandmarken und den Tatbestand der Irrlehre zu erhärten. Das zeigt sich bereits zuvor, wenn er sagt: „Novam autem inventionem alienam esse ab Ecclesiastica doctrina ... Dass es sich um eine neue Erfindung handelt, die der kirchlichen Lehre gegenüber fremd ist ..." (Opuscula omnia Thomae de Vio Caietani Cardinalis tituli sancti Syxti in tres distincta tomos, Lyon 1588, S. 110, 16f.).

3 John Glynmor, Congregationalism in the Early Continental Reform, Congregational Studies 1, London 1963, S. (1-7) 4 (Übersetzung nach Hartmut Weyel, „Geschichte des Bundes Freier evangelischer Gemeinden in Deutschland“ in: Johannes Demandt (Hg.), Freie evangelische Gemeinden, Die Kirchen der Gegenwart 4 = Bensheimer Hefte 114, Göttingen 2012, S. 14-35) sieht die freikirchlichen Gemeindebildungen generell als „Antwort einer autonomen Frömmigkeit außerhalb einer verfallenden Kirche auf die tiefen Nöte, die durch die Lehre dieser Kirche selbst entstanden waren“, an; zu den Begriffen und deren historischer Entwicklung siehe: Rüdiger Schloz, „Kirchenreform“ in: Theologische Realenzyklopädie 19, Berlin-New York 1990, S. 51-58 sowie Jan Hermelink, „Organisation der christlichen Freiheit. Beispiel, Tendenzen und Programme gegenwärtiger Kirchenreform “ in: Theologische Literaturzeitung 128 (2003), S. 127-138; zu den in Deutschland im 19. Jahrhundert entstandenen Freikirchen siehe: Karl Heinz Voigt, Freikirchen in Deutschland (19. und 20. Jahrhundert), Kirchengeschichte in Einzeldarstellungen 3/6, Leipzig 2004.

4 Vgl. Johannes Demandt, „Christliche Lehre in Freien evangelischen Gemeinden. Eine Skizze“ in: Idem (Hg.), Freie evangelische Gemeinden, Die Kirchen der Gegenwart 4 = Bensheimer Hefte 114, Göttingen 2012, S. 36-53 betont, dass es bei der Gründung der ersten 
von reformatio zu sprechen, ist auch deswegen in Bezug auf die Entstehung der Freien evangelischen Gemeinden sachgerecht, weil reformatio unter den gewandelten Bedingungen der Neuzeit nach der Französischen Revolution im Gegensatz zur Revolution eine gewaltfreie Weiterentwicklung bezeichnet. Allerdings ist der Begriff heute diffus, denn er beschreibt allgemeine Prozesse der Anpassung von Ideen, Methoden und Institutionen, sodass Reform überhaupt zum Modus einer evolutionären Modernisierung geworden ist ${ }^{5}$.

Im Folgenden wird die geschichtliche Entwicklung der Anfänge der Freien evangelischen Gemeinden unter dem Aspekt der Erneuerung nachgezeichnet. Sodann wird gefragt, was genau aus dem Ideal der Frühkirche rezipiert und als Leitbild erneuert wird.

\section{Die Freien evangelischen Gemeinden als Erneuerungsbewegung}

Die Freien evangelischen Gemeinden haben heute deutschlandweit ca. 450 Gemeinden mit etwa 38500 Mitgliedern, was ca. 0,5 Promille der Bevölkerung entspricht ${ }^{6}$. Geografische Schwerpunkte bilden der südwestfälisch-mittelhessische Raum und der Großraum Hamburg. Wenig vertreten sind die Freien evangelischen Gemeinden im Osten Deutschlands ${ }^{7}$. International hat die „International Federation of Free Evangelical Churches“ mit Kindern und Freunden etwa eine Million Mitglieder. Im Vergleich zu anderen konfessionellen Weltbünden ist sie eine kleine Organisation, zählen doch beispielsweise zum Lutherischen und Baptistischen Weltbund, zum Weltrat der Methodistischen Kirchen oder zur Weltgemeinschaft Reformierter Kirchen jeweils zwischen 50 und 100 Millionen Menschen ${ }^{8}$.

Die Freien evangelischen Gemeinden verstehen sich geschichtlich und auch theologisch als Gemeinden Jesu Christi. Dabei schließen sie sich an die Reformation des 16. Jahrhunderts und speziell an die Erweckungsbewegung des 19. Jahrhunderts an. Sie teilen mit den evangelischen Landeskirchen so-

Freien evangelischen Gemeinde in 1854 „keineswegs um einen ekklesiologischen Perfektionismus" ging, sondern man „lediglich das neutestamentliche Prinzip der Gemeinde von Glaubenden umsetzen"wollte.

5 Vgl. Martin Honecker, Evangelisches Kirchenrecht. Eine Einführung in die theologischen Grundlagen, Bensheimer Hefte 109, Göttingen 2009, S. 288.

6 Vgl. Reinhard Henkel, „Die geographische Verbreitung Freier evangelischer Gemeinden“ in: J. Demandt (Hg.), Freie evangelische Gemeinden, S. 54-69 mit Stand vom Januar 2011 überholt die Zahlenangaben bei Günter Balders, „Freie evangelische Gemeinden/Bund Freier evangelischer Gemeinden in Deutschland“ in: Religion in Geschichte und Gegenwart ${ }^{4}$ 3, Tübingen 2000, S. 300.

7 R. Henkel, „Die geographische Verbreitung“, S. 64.

8 Vgl. Ibidem, S. 62 und http://www.iffec.org/ (abgerufen am: 31.12.2014). 
wie mit anderen evangelischen Freikirchen und Gemeindebünden das Erbe der Reformation?.

Auch darin, wie Gemeinde verstanden wird, beerben die Freien evangelischen Gemeinden wenigstens Luthers Vorrede zur Deutschen Messe von $1526^{10}$. Darin beschrieb er als wünschenswerte Gemeindeform den Gottesdienst derer, „die mit Ernst Christen sein“ wollen.

Die reformatio der Freien evangelischen Gemeinden besteht in ihrer Auffassung, dass Gottes Wort erst da zu seinem Ziel kommt, wo es menschlichen Glauben weckt und im Gehorsam des Glaubens angenommen wird. Wer auf Gottes Wort hört, wird als Hörer verändert. Er wird in die Gemeinschaft aller Glaubenden versetzt. Die Gemeinde ist darum der Ort, in dem dieses glaubensweckende Wort gehört werden kann. Sie ist auch der Ort für das auf das Wort Gottes antwortende Bekenntnis in Wort und Tat.

Um die Reform in dieser Erneuerungsbewegung zu beschreiben, bietet sich ein personengeschichtlicher Zugang an, da sich im Leben Hermann Heinrich Grafes, der am 3. Februar 1818 in Palsterkamp bei Dissen am Rande des Teutoburger Waldes geboren wurde, exemplarisch die ekklesiologische Erneuerung spiegelt, die für Freie evangelische Gemeinden prägend bleiben wird ${ }^{11}$.

9 Im Zentrum dieses lebendigen Erbes steht für die Freien evangelischen Gemeinden seit Hermann Heinrich Grafe das Evangelium als frohe Botschaft von Gottes freier Gnade für die in Sünden gefangenen Menschen. Der rettende Glaube ist nichts, was Menschen aus sich selbst hervorbringen oder besitzen könnten. Er wird allein von Gott ermöglicht. Die Reformatoren drückten dies in den vier „solae“ aus. Allein Christus mit seinem Leben, Sterben und Auferstehen ermöglicht die Gemeinschaft des Menschen mit Gott. Allein die Heilige Schrift, die von Christus zeugt und sein Leben und Werk durch den Heiligen Geist für den Menschen erfahrbar macht, tritt an die Stelle der kirchlichen Lehrautorität. Allein aus Gnade wendet Gott sich dem Menschen zu. Das Heil ist somit an keine Bedingung geknüpft, sondern liegt außerhalb der Menschen begründet. Die Aneignung der Gnade geschieht allein aus Glauben seitens des Menschen. Der Glaube ist aber ein gnadengewirktes Geschenk von Gott. Deshalb kann man nie vom Glauben des Menschen reden, ohne auf die Gnade Gottes zu verweisen; vgl. Markus Iff, „Der Wort-Gottes-Begriff Martin Luthers (verbum efficax) in seiner Bedeutung für die Soteriologie und Ekklesiologie Freier evangelischer Gemeinden“ in: Volker Spangenberg (Hg.), Luther und die Reformation aus freikirchlicher Sicht, Kirche - Konfession - Religion 59, Göttingen 2013, S. 153-170 sowie: Verein für Freikirchenforschung (Hg.), Die Rezeption der Wittenberger Reformation in den Freikirchen und Die Rezeption der oberdeutschen-schweizerischen Reformation in den Freikirchen, Freikirchenforschung 20, Münster 2011.

10 WA 19, 73-75; vgl. M. Iff, „Reformation und Reformationsgedenken aus freikirchlicher Sicht“ in: Catholica 68 (2014), S. 260-275.

11 Biografien: Heinrich Neviandt, „Erinnerungen aus dem Leben des am 25. Dezember 1869 entschlafenen Kaufmannes Hermann Heinrich Grafe“, in: Wolfgang Dietrich, (Hg.), Ein Act des Gewissens. Erinnerungen an Hermann Heinrich Grafe, unter Mitarbeit v. Erich Brenner et al., Geschichte und Theologie der Freien evangelischen Gemeinden 1, Witten 1988, S. 99-284; Gustav Ischebeck, „Blätter aus vergangenen Tagen“ in: Der Gärtner, Nr. 37/38 (22.9.1918), S. 162, Nr. 51 (21.12.1919), S. 300; Walther Hermes, Hermann Hein- 


\subsection{Hermann Heinrich Grafe - ein Leben der Erneuerung}

Wenn man nach der Erneuerung im Leben Grafes fragt, dann ist man vor allem auf seine Tagebücher als Quelle angewiesen. Darin legte er seit 1851 nahezu kaufmännisch sich selbst, der Nachwelt und Gott Rechenschaft über seine Entwicklung ab. Die Ergebnisse seiner Studien hielt er über 15 Jahre lang in Tagebüchern fest. Von den ursprünglich acht Bänden sind sieben im Archiv der Freien evangelischen Gemeinde in Elberfeld-Barmen erhalten. Der dritte Band mit den Aufzeichnungen der Jahre 1854/1855 ist bis heute verschollen $^{12}$. In seinen Tagebüchern versteht Grafe die christliche Wahrheit als existentielle „Wahrheit des Lebens“. Man könne ihr höchstens „nachdenken“, denn die „Tätigkeit des Herzens“ sei der „des Kopfes immer voraus ..." ${ }^{13}$. Die christliche Wahrheit hat für Grafe das neue Leben des Menschen zum Inhalt. Es sei daher Aufgabe der Theologie, dieses Leben zu beschreiben, in der Art, wie es sich im Menschen darstellt. Die ersten beiden Tagebücher, die für den Zeitraum bis 1854 maßgeblich sind, tragen daher den Namen „Lebenszeichen oder Selbststudien in Form eines Tagebuchs.“ Das Genre, dessen Grafe sich in seinen Tagebüchern bedient, ähnelt eher den Traktaten „Über die Bestimmung des Menschen“, die seit Johann Joachim Spaldings populärem Entwurf ${ }^{14}$

rich Grafe und seine Zeit. Ein Lebens- und Zeitbild aus den Anfängen der westdeutschen Gemeinschaftsbewegung. Mit einem Anhang der Lieder und Gedichte Grafes, Witten 1933; Richard Hoenen, Die Freien evangelischen Gemeinden in Deutschland. Ihre Entstehung und Entwicklung, Tübingen 1930; Wolfgang E. Heinrichs, Freikirchen. Eine moderne Kirchenform. Entstehung und Entwicklung von fünfFreikirchen im Wuppertal, Monographien und Studienbücher, Wuppertal 1989; Idem, „Hermann Heinrich Grafe und seine Zeit“, in: Wilfrid Haubeck et al. (Hg.), Lebenszeichen. Die Tagebücher Hermann Heinrich Grafes in Auszügen, Wuppertal-Witten 2004, S. 13-26; H. Weyel, Zukunft braucht Herkunft. Lebendige Portraits aus der Geschichte und Vorgeschichte der Freien evangelischen Gemeinden, Geschichte und Theologie der Freien evangelischen Gemeinden 5.5/1-3, Witten 2009-2011 (darin Portraits zu nahezu allen hier verhandelten frei-evangelischen Personen); Idem, Evangelisch und frei. Geschichte des Bundes Freier evangelischer Gemeinden in Deutschland, Geschichte und Theologie der Freien evangelischen Gemeinden 5.6, Witten 2013, S. 18-37.

12 Über die Fundgeschichte informiert: August Jung, Tradition auf Umwegen, in: W. Dietrich (Hg.), Ein Act des Gewissens, S. 39-70. Eine Auswahlausgabe der von Gertrud Lützenbürger transkribierten Texte liegt vor in: W. Haubeck et al. (Hg.), Lebenszeichen; eine digitale Gesamtausgabe in Umschrift bietet: Lebendige FeG-Geschichte. Historische Dokumente zur Entwicklung der Freien evangelischen Gemeinden, red. Arnd Schnepper, Witten o.J.; Hartmut Lenhard, Die Einheit der Kinder Gottes. Der Weg Hermann Heinrich Grafes (1818-1869) zwischen Brüderbewegung und Baptisten, Witten-Wuppertal 1977, S. 91-94.

13 Tagebucheintrag vom 18. Juni 1852, Tagebuch 1, 151; vgl. H. Lenhard, Die Einheit der, S. 92; vgl. auch den Eintrag vom 19. Juni 1852, in: W. Haubeck et al. (Hg.), Lebenszeichen, S. 87-89.

14 Johann Joachim Spalding, Betrachtung über die Bestimmung des Menschen, dritte und vermehrte Auflage, Berlin 1749. 
bis hin zu Fichtes „Bestimmung des Menschen“ von $1800^{15}$ gerade in der Jugendzeit Grafes enorme Auflagen hatten ${ }^{16}$. Augenfällig ähnelt die moralische Bestimmung des Endzwecks menschlichen Daseins bei Grafe den Zielen dieser Traktate. Aufgrund des leitenden ethischen Interesses kreist er in den Selbststudien um Themen wie Sünde und Gnade, Bekehrung und Wiedergeburt, vor allem aber um die Heiligung, denn Grafe ist überzeugt, dass das sittliche Verhalten der höchste Beruf des Christen sei, dem er „alles im Leben unterordnen und dienstbar machen soll“"17.

Bereits als Kind überzeugte der willensstarke Grafe seine Eltern davon, ihn auf die Gewerbeschule nach Bielefeld zu schicken. 1834 begann er seine Arbeit in einer Baumwollfabrik in Duisburg. Die Textilindustrie wurde in dieser Zeit der Leitsektor für die einsetzende industrielle Erneuerung. Besonders in dieser Region waren die Ausbildungsbedingungen für Textilkaufleute hervorragend ${ }^{18}$.

Grafe lernte dort jedoch nicht nur den ökonomischen Fortschritt kennen. Er bekam auch Kontakt zu Kreisen der Erweckungsbewegung, die Erneuerung auf geistlichem Gebiet suchten. Erneuerung war im Bereich der Politik, der Wirtschaft und der Gesellschaft in dieser Zeit überall im

15 Johann Gottlieb Fichte, „Die Bestimmung des Menschen“ in: Gesamtausgabe der Bayerischen Akademie der Wissenschaften, Abteilung 1, Bd. 6: Werke 1799-1801, hg. v. Reinhard Lauth et al., Stuttgart-Bad Cannstatt 1981, S. 145-311.

16 Fotis Jannidis, „Die «Bestimmung des Menschen»-Kultursemiotische Beschreibung einer sprachlichen Formel“, in: Aufklärung 14 (2002), S. 75-95 zeigt die Erstdrucke und Neuauflagen in der Zeit zwischen 1740 und 1850 und gibt eine Bibliografie der selbständig erschienenen Texte, die die Formel „Bestimmung des Menschen“ oder „Bestimmung der Menschheit" oder eine deutlich erkennbare Variation dieser Formel im Titel tragen.

17 Tagebucheintrag vom 17. Januar 1852 (Tagebuch 1, 55).

18 Die Arbeiten des Wuppertaler Historikers Wolfgang Heinrichs werten die Entstehungsgeschichte der Freikirchen im deutschen Raum für die Mentalitätsgeschichte der Moderne aus. Er geht davon aus, dass religiös geprägtes Denken als fundamentale Interpretation der Welt und als Antwort auf die konkrete Frage der Lebensbewältigung in Kohärenz mit an der Umwelt orientiertem Handeln steht, siehe: W.E. Heinrichs, Freikirchen, S. 2. Erstmals wird die Geschichte der Freien evangelischen Gemeinden als Regionalgeschichte reflektiert. $\mathrm{Da}$ „Mentalität“ als „innere Disposition“, „die in einer engen Relation zu äußeren sozialen Konstellationen steht“, aufgefasst wird, gehören Mentalität und Zivilisation zusammen. Und Zivilisation sei in einem klar umrissenen historischen Raum, nämlich der Region zu fassen, siehe: Ibidem, S. 5. In dem exemplarischen Mikrokosmos des Wuppertals wird die Struktur des Ganzen sichtbar. Darum lassen sich Freikirchen als „Antwort des Protestantismus auf die moderne Welt" verstehen und stellen als „Übersetzung der neuen sozialen Organisationsform des Vereins ins Religiöse“ eine „moderne ekklesiologische Alternative zur Amts- bzw. Landeskirche“ dar, siehe Ibidem, S. 16; vgl. Andreas Heiser, „Wie man Geschichte schreiben soll. Historische Skizze einer frei-evangelischen Historik“ in: Theologisches Gespräch 36, Jahrgang, 3 (2012), S. 128-147. 
Gang $^{19}$. Grafe kam hier zu der Einsicht, dass gerade in der Zeit der beschleunigten Veränderung, der Entdeckung neuer Möglichkeiten und der Entfesselung des menschlichen Geistes und seiner Möglichkeiten auf allen Gebieten des Daseins auch die Frage nach dem Sinn der Existenz neu beantwortet werden müsse. Er fand diese Antwort schließlich in der Erneuerung des evangelischen Glaubens. Später formulierte er seine Einsicht so, dass dieser Glaube „individuell“ erfahren und gemeinschaftlich kommuniziert werden müsse. Fortan war dieser Glaube für ihn ein Kontrapunkt zu einer Emanzipation des Menschen, der sich auf nichts mehr weiter zu beziehen wusste als auf sich selbst.

Für Grafes eigene Entwicklungen wurde entscheidend, dass er mit Eduard Neviandt (1819-1887) zusammentraf, der aus einem frommen, pietistischen Fabrikantenhaus stammte ${ }^{20}$. Durch ihn wurde Grafe veranlasst, nach seiner Lehrzeit als Handlungsgehilfe in dem Geschäft von Karl Wilhelm Neviandt (1792-1870) zu arbeiten. So kam Grafe in eine Familie aus hugenottischer Tradition. Deren Haus in Mettmann war ein Mittelpunkt der Erweckungsbewegung auf der Grenze zwischen Niederrhein und dem Bergischen Land. Neviandt bemühte sich dort um die Einheit der „Erweckten“" und besonders um die konfessionsübergreifende „Volksmission“. Er war in 1848 einer der Mitbegründer der „Evangelischen Gesellschaft für Deutschland“21 und in 1850 des „Evangelischen Brüdervereins“"22. Von dem ambitionierten jungen Mann war Neviandt so beeindruckt, dass er ihm nicht nur die Tochter zur Frau überließ, sondern ihm auch empfahl, mit seinem Sohn Eduard eine Firma in Elberfeld zu gründen, womit er auf die wachsende Nachfrage nach Seidenstoffen in bester Qualität reagierte. Zudem erkannte K.W. Neviandt wohl aber auch in seinem Schwiegersohn einen möglichen Nachfolger für die Führung der bergisch-niederrheinischen Erweckungsbewegung.

19 Vgl. Karl-Hermann Beeck, Rolf Becker (Hg.), Gründerzeit. Versuch einer Grenzbestimmung im Wuppertal. Abhandlungen und Spezialbibliographie, Schriftenreihe des Vereins für Rheinische Kirchengeschichte 80, Köln-Bonn 1984.

20 Vgl. Wolfgang E. Heinrichs, „Hermann Heinrich Grafe und seine Zeit“ in: W. Haubeck et al. (Hg.), Lebenszeichen, S. 13-26.

${ }_{21}$ Vgl. Karl Halaski, „Evangelische Gesellschaft, 3. Für Deutschland“ in: Die Religion in Geschichte und Gegenwart ${ }^{3}$ 2, Tübingen 1958, S. 778; Wilfred Hoffmann, „Evangelische Gesellschaft für Deutschland - Neukirchener Mission“ in: Evangelisches Lexikon für Theologie und Gemeinde 1, Wuppertal 1992, S. 565; in 1974 schloss sich die Evangelische Gesellschaft für Deutschland mit der Neukirchener Mission zusammen; vgl. Bernd Brandl, Die Neukirchener Mission. Ihre Geschichte als erste deutsche Glaubensmission, Schriftenreihe des Vereins für Rheinische Kirchengeschichte 128, Köln-Neukirchen-Vluyn 1998.

22 Zur Erneuerung durch den Evangelischen Brüderverein siehe unten S. 15. 


\subsubsection{Die Erneuerung des Réveil}

Vor seiner Heirat mit Maria Theresia Neviandt (1824-1871) sollte Grafe sich in den neuesten Fabrikationstechniken in Lyon fortbilden. Zudem knüpfte er von dort aus Geschäftsbeziehungen nach England und in die französische Schweiz. In dieser Zeit bekam er aber auch den entscheidenden Impuls für eine kirchliche Erneuerung. Er schloss sich in Lyon der „Église libre évangelique de Lyon" an, die von dem Erweckungsprediger Adolphe Monod (1802-1856) gegründet worden war ${ }^{23}$. Zunächst war er von der diakonischen Arbeit dieser Gemeinde beeindruckt, die sich in der frühindustrialisierten Textilmetropole besonders um die Armen der Stadt kümmerte. Den Kindern aus den ärmeren Schichten wurde ein elementarer Unterricht angeboten. Während sonst die sozialen Schichten in der frühen Industrialisierung zerklüfteten, vollzog sich die Integration in Lyon auf für Grafe vorbildliche Weise. Dies geschah hier auf der Basis einer Einheit von Lehre und Leben. Alle Gemeindeglieder beachteten einen Glaubens- und Sittenkonsens, der durch die Anwendung der altreformierten Gemeindezucht auch mit aller Konsequenz evaluiert wurde ${ }^{24}$. Grafe wurde Mitglied in dieser Gemeinde und arbeitete in der "Sonntagschule“ mit. Hier in Lyon und auch auf seinen späteren Geschäftsreisen lernte er ein neues Verständnis von Kirche kennen, das ihn später dazu veranlasste, die erste Freie evangelische Gemeinde auf deutschem Boden zu gründen.

Es war zudem vor allem der ekklesiologische Entwurf des Schweizer Erweckungspredigers und Gemeindegründers Auguste Rochat (1789-1847), der für Grafe Modellcharakter bekam. Im Mittelpunkt stand nun zunehmend

23 Vgl. Ulrich Gäbler, „Auferstehungszeit“. Erweckungsprediger des 19. Jahrhunderts. Sechs Portraits, München 1991, S. 55-81 und 190; Wolfgang E. Heinrichs, „Monod, Adolphe“ in: Biographisches-Bibliographisches Kirchenlexikon 6, Herzberg 1993, S. 62-65 und H. Weyel, Zukunft braucht Herkunft, S. 97-109. Ich danke Hartmut Weyel für den schriftlichen Hinweis darauf, dass Grafe, der Ende 1841 nach Lyon kam, Monod dort nicht mehr erlebt hat, da dieser schon 1836 einen Lehrstuhl in Montauban angenommen hatte. Sein Nachfolger in Lyon zur Zeit Grafes war der Welschweizer Georg Fisch (1841-1881). Unter dem Eindruck von dessen Verkündigung hat Grafe wohl eine existentielle Erfahrung der „freien“ Gnade gemacht.

24 Im Heidelberger Katechismus von 1563 wurde erklärt, dass solche, „die sich in ihrem Bekenntnis und Leben als Ungläubige und Gottlose erweisen“, nicht zum Abendmahl zugelassen werden dürfen, weil „sonst der Bund Gottes geschmäht und sein Zorn über die ganze Gemeinde erregt wird." (Frage 82, in: Heidelberger Katechismus. Revidierte Ausgabe, Neukirchen-Vluyn 1997, S. 54). Adolphe Monod war wegen seiner öffentlichen Klarstellung, wer am Abendmahl teilnehmen dürfe, von seinem Amt als reformierter Pastor suspendiert worden. Vgl. seine Predigt: Qui doit communier? Sermon prêché à Lyon le 20 Mars 1831, Paris-Genf 1831. 
das Motiv der Einheit der Gemeinde Jesu Christi ${ }^{25}$. Diese Einheit ergab sich für ihn zuerst als Einheit der Erwählung, sodann als Einheit des Glaubens und des aus dem Glauben gelebten Lebens. Fasziniert war Grafe von dem Gedanken, dass die wirklich Glaubenden scharf von denen zu unterscheiden seien, die sich nur noch formal, ohne rechte Überzeugung und die aus dieser motivierten Lebensführung zum Christentum hielten.

Nach seiner Zeit in Lyon sah Grafe den Ort für die Darstellung der Einheit in dem Abendmahl, an dem kein Ungläubiger teilnehmen soll. Als ungläubig sah er diejenigen an, die sich nur noch rein äußerlich zur Kirche hielten, nicht aber mit innerer Überzeugung.

Die brodelnde innere Entwicklung, die durch die Lyoner Erfahrungen angestoßen war, führte nicht unmittelbar zu einer eigenen kirchlichen Erneuerung. Nachdem Grafe zurückgekehrt war, zog er 1843 nach Elberfeld. Mit den erworbenen Kenntnissen in der Jacquardschen Webtechnik, die ihm die Fertigung von Webwaren in großen Rapporten ermöglichten, gründete er zusammen mit Eduard Neviandt eine Firma für seidene, halbseidene und halbwollene Waren. In dieser frühindustrialisierten Region zählte sie bald unter die renommierten Unternehmen ${ }^{26}$.

Auch kirchlich orientierte sich Grafe nach dem Kontakt mit der Lyoner Erweckungsbewegung neu. In Elberfeld schloss er sich der reformierten Gemeinde an. Sie war von Pfarrern geprägt, die der Erweckungsbewegung nahestanden. Die Gemeinde wurde von einem Presbyterium und einer größeren Repräsentation geleitet. Nach der neuen Kirchenordnung wurde die Gemeindevertretung demokratisch gewählt. Zur Wahl standen jedoch nur solche Männer, die in der Stadt wegen ihres sozialen Engagements über gutes Ansehen verfügten. In dieser Zeit waren politische, soziale und ökonomische Fähigkeiten in der kirchlichen Arbeit existentiell. Darum wundert es nicht, dass man Grafe in die größere Repräsentation wählte. Er übernahm darin das Amt eines Diakons, in dem er die Erfahrungen aus Lyon reflektieren konnte. Nicht zuletzt deswegen geriet er bald in den Konflikt mit dem Presbyterium. Er fehlte absichtlich und unentschuldigt in einer Sitzung, in der über die Einführung der Kirchensteuer beraten wur-

25 Vgl. H. Lenhard, Studien zur Entwicklung der Ekklesiologie in den Freien evangelischen Gemeinden in Deutschland, Wuppertal-Witten 1977 und Idem, Die Einheit der Kinder Gottes.

26 In der von der Elberfelder Stadtverwaltung für 1852 geführten Statistik wurde die Firma in ihrem Ortsbereich unter die „bedeutenden Manufakturwaren-Fabriken“ gerechnet. Vgl. W.E. Heinrichs, „Hermann Heinrich Grafe“, S. 16 und Hermann Herberts, Alles ist Kirche und Handel ... . Wirtschaft und Gesellschaft des Wuppertals im Vormärz und in der Revolution 1848/1849, Bergische Forschungen 12, Neustadt a. d. Aisch 1980, S. 54 und S. 228. 
de. Er selbst sah diese Steuer als eine „unevangelische, heidnisch-gläubige Zwangsmaßregel“ $\mathrm{an}^{27}$.

Hier wird erstmals greifbar, wie Grafe ausgehend von einer im Neuen Testament beschriebenen Struktur die gegenwärtigen kirchlichen Verhältnisse kritisierte und sein eigenes Verhalten nach einem als zeitlos gültig verstandenen neutestamentlichen Idealbild erneuerte. Er erklärte also der Gemeindeleitung, dass er vom neutestamentlichen Prinzip der Freiwilligkeit ausgehe. Dieses sei in den Kollektenreden des Apostels Paulus auch in Bezug auf die Abgaben für die Gemeinde formuliert ${ }^{28}$.

Der innere Bruch mit dem landeskirchlichen Kirchenmodell war zu Anfang der 1850er Jahre bereits seit zehn Jahren vollzogen. Es hielten Grafe aber noch zwei Gründe davon ab, die Konsequenzen aus seiner Erkenntnis zu ziehen. Der eine bestand in der Rücksicht auf die Glaubensgeschwister. Er wollte sich von ihnen nicht trennen, denn auch innerhalb der Kirche gab es für ihn noch die wirklich Glaubenden. Seit seiner Lyoner Zeit finden wir Äußerungen darüber, dass er als wahre Gemeinde nur die Gemeinschaft der Glaubenden ansah und eben nicht die Zusammenkunft all derer, die sich formal zur Kirche hielten, aber mit dem Herzen nicht dabei waren ${ }^{29}$. Immerhin gehörte Grafes Verwandtschaft und auch viele Freunde zur reformierten Gemeinde in Elberfeld. Auch die damalige Verkündigung wird man als schriftgemäß beschreiben können ${ }^{30}$. Deswegen war die Hoffnung für Grafe noch nicht ganz getrübt, dass es innerhalb der bestehenden Kirche zu einer Erneuerung kommen könnte.

Es bestand aber noch ein zweiter Grund dafür, warum Grafe sich zu dieser Zeit noch keiner Freikirche anschloss oder gar eine eigene Freikirche ins Leben rief. Noch bestand in Deutschland keine verfassungsrechtliche Grundlage für die Gründung einer Freikirche. Es musste in Deutschland erst zu einer Revolution kommen.

27 Vgl. Außerordentliche Sitzung des Presbyteriums der reformierten Gemeinde Elberfelds vom 5. Dezember 1844, in: Presbyteriumsprotokolle (Archiv der reformierten Gemeinde Elberfelds); W. Dietrich (Hg.), Ein Act des Gewissens, S. 142; W.E. Heinrichs, „Hermann Heinrich Grafe", S. 17 und H. Weyel, Evangelisch und frei, S. 21.

28 W.E. Heinrichs, „Hermann Heinrich Grafe“, S. 17.

29 Grundsätzliche Bedenken schildert H. Weyel, Evangelisch und frei, S. 14.

30 Grafe besuchte oft die Gottesdienste, in denen der reformierte Pfarrer und spätere Hofprediger in Potsdam Friedrich Wilhelm Krummacher (1796-1868) predigte; vgl. H. Weyel, Evangelisch und frei, S. 19; zu Krummacher siehe: Otto von Ranke, „Krummacher, Friedrich Wilhelm“ in: Allgemeine Deutsche Bibliographie 17, Leipzig 1883, S. 243-246 und HermannPeter Eberlein, Album ministrorum der reformierten Gemeinde Elberfeld. Prediger und Pastoren seit 1552, Schriftenreihe des Vereins für Rheinische Kirchengeschichte 163, Bonn 2003, S. 106-111. 


\subsubsection{Die politische Erneuerung}

Die kirchlichen Erneuerungsbewegungen in der Mitte des 19. Jahrhunderts hängen unmittelbar mit dem Wandel der politischen Verhältnisse zusammen. Erst nach langen Auseinandersetzungen und teils harten Verfolgungen wurden in Preußen die Altlutheraner als erste Freikirche durch die „General-Konzession für die Gemeinschaft der evangelischen Landeskirche sich getrennt haltenden Lutheraner" am 23. Juni 1845 anerkannt $^{31}$. Eine erste Freikirche im Wuppertal bildete sich ebenfalls aus der reformierten Gemeinde Elber-

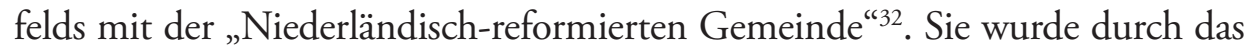
„Patent, die Bildung neuer Religions-Gesellschaften betreffend“ am 30. März 1847 zugelassen. Erst nachdem die verschiedenen Staaten im deutschen Raum als Reaktion auf die Revolution 1848/1849 in ihren Verfassungen entsprechende staatsrechtliche Regelungen formuliert hatten, konnten andere Religionsgemeinschaften unabhängig von den bestehenden Kirchen gegründet werden.

Die politischen und gesellschaftlichen Neuerungen nahmen um die Jahrhundertmitte einen rasanten Verlauf. Das Bürgertum formulierte zunehmend seinen Anspruch auf Mitbestimmung. Die verarmten unteren Schichten artikulierten die Not der vorindustriellen Massenarmut, die aus dem Abbruch des alten, auf Grundherrschaft und Zunftverfassung beruhenden Gesellschaftsgefüges, entstanden war ${ }^{33}$.

In der Revolution von 1848/1849 entlud sich dieser Sprengstoff. Grafe erlebte die Unruhen hautnah mit, als in Elberfeld am 9. Mai 1849 mitten in der Reichsverfassungskampagne (April bis Juli 1849) ein Aufstand losbrach, der zu Barrikadenkämpfen und Ausschreitungen gegen das Besitzbürgertum der Stadt führte. Wie auch in anderen Städten ${ }^{34}$ wurde der Aufstand in El-

31 Vgl. Gerhard Robbers, „Das Verhältnis der evangelischen Landeskirchen und Freikirchen. Aspekte der staatsrechtlichen Grundlagen im Preußen des 19. Jahrhunderts“, in: epd-Dokumentation 9 (2014), S. 27-33 und W.E. Heinrichs, Freikirchen, S. 167-278.

32 Vgl. Klaus van Bürck, Heinrich Lüchtenborg, Niederländisch-reformierte Gemeinde Elberfeld. 150 Jahre Niederländisch-reformierte Gemeinde zu Elberfeld, Wuppertal 2000 und W.E. Heinrichs, Freikirchen, S. 23-166.

33 Vgl. Lothar Gall, „Von der ständischen zur bürgerlichen Gesellschaft“ in: Enzyklopädie Deutscher Geschichte 25, 2., aktualisierte Auflage, München 2012, S. 89-97 und Alexis de Tocqueville, Das Elend der Armut. Über den Pauperismus, Manfred Füllsack, Michael Tillmann (Hg.), Berlin 2007.

34 Im Oktober 1848 wurde die Revolution in Wien militärisch niedergeworfen. In Berlin verschärfte sich die Gegenrevolution, deren Sitzungen durch die Preußische Nationalversammlung am 9. November 1848 verboten worden waren. Der preußische König Friedrich Wilhelm IV. lehnte die ihm von der Nationalversammlung angebotene Kaiserkrone harsch ab; vgl. W.E. Heinrichs, „Hermann Heinrich Grafe“, S. 18. 
berfeld durch preußisches Militär niedergeschlagen ${ }^{35}$. Für Grafe war der bewaffnete Aufstand der Ausfluss eines krankhaften Zeitgeistes und darum als gottlos und verwerflich abzulehnen. Die radikale Forderung nach freiheitlicher Emanzipation führe in einen Emanzipationszwang. „In der damaligen Bewegung“, sagte er rückblickend, „sah ich nur Schlechtes und in dem Festhalten am Alten meistens nur Gutes. “36

In seinen im November 1851 begonnenen Tagebucheinträgen setzte er sich mit den emanzipatorischen Gedanken auseinander. Er sah sie in der Philosophie Georg Wilhelm Friedrich Hegels (1770-1831) verankert. Man kann nicht sagen, dass Grafe den Hegelschen Entwurf bis ins letzte durchdrungen hat. Grafe vertrat eine nicht weiter reflektierte Position des Realismus, wie sie von Friedrich Heinrich Jacobi (1743-1819), in Teilen auch von Johann Gottfried Herder (1744-1803) und Friedrich W. J. Schelling (1775-1854) begründet wurde. Hier geht es, vereinfacht gesprochen, um die anticartesianisch geprägte Voranstellung des sum vor dem cogito. Häufig bietet seine Selbstreflexion lediglich Ausführungen zu aufgenommenen Stichwörtern wie „Weltgeist“, „Freiheit“ und allem voran „Wahrheit“. Da Grafes voluntaristischer Ansatz auf Erfahrung gründete, geriet er zwangsläufig in den Gegensatz zu Hegel. Dabei lehnen sich Grafes Auffassungen deutlich an die seines Zeitgenossen Sören Kierkegaards (1813-1855) an. Der Mensch sei niemals frei an und für sich. Erst in der Gemeinschaft mit Gott und aus der Lösung von der Sünde gewinne er Freiheit. Die Erfahrung der eigenen Sündhaftigkeit

35 Vgl. Klaus Goebel, Manfred Wichelhaus (Hg.), Aufstand der Bürger. Die Revolution 1849 im westdeutschen Industriezentrum, Wuppertal 1974 und Wolfgang Dietrich, Barrikaden. Heimatmission und Gemeindediakonie, in: Idem (Hg.), Ein Act des Gewissens. Dokumente zur Frühgeschichte der Freien evangelischen Gemeinden, unter Mitarbeit v. Erich Brenner et al., Geschichte und Theologie der Freien evangelischen Gemeinden 2, Witten 1988, S. 11-54.

36 In der Zeit danach vollzog sich ein Wandel seiner politischen Auffassung. Er zog nun die demokratische Staatsform der Monarchie vor. „Und sollte ich unter den verschiedenen Regierungsformen wählen, so würde ich keine Bedenken tragen, mich für eine Republik, als für die an sich beste, zu erklären; weil sie der persönlichen Entwicklung, zur Bildung tüchtiger Charaktere, am förderlichsten ist, indem ihre Handhabung, wenn solche wirklich ersprießlich sein soll für das Wohl des Landes, schon Charaktere verlangt, die aus dem Volke hervorgegangen und in ihm gebildet, dann auch auf's Volk volksthümlich zurückwirken und dasselbe zur eigenen Bildung soviel besser anspornen können." (Tagebucheintrag vom 21. Juni 1852, Tagebuch 1, S. 158-161); vgl. W.E. Heinrichs, Freikirchen, S. 396 mit Anm. 312, auf S. 599: Grafe wurde später Ehrenmitglied im konservativen „christlichen Bürgerverein“, woraus deutlich wird, wie seine Loyalität zur preußischen Krone geschätzt wurde; Grafe gibt sich auch durchaus weiterhin demokratiekritisch. Die Minderheit müsse sich aufgrund von Zahlenverhältnissen in ihren Entscheidungen auch gegen ihr Gewissen häufig der Mehrheit beugen; vgl. Ibidem, S. 399. 
bewirke die Sehnsucht nach der Erlösung und der Befreiung aus einem entfremdeten Leben ${ }^{37}$.

\subsubsection{Die Erneuerung durch den Evangelischen Brüderverein}

Es sind äußere und innere Umstände zugleich, die Grafe durch die Erfahrung der Revolution zum Handeln bewegten. Es verfestigte sich der Gedanke, dass die evangelische Landeskirche in ihrer bisherigen Struktur nicht länger eine ausreichende Plattform für eine grundlegende Erneuerung bot. Darum gründete Grafe mit Gleichgesinnten am 3. Juli 1850 in Elberfeld als landeskirchlich ungebundenen Verein den „Evangelischen Brüderverein“38. Inzwischen waren in den Artikeln 29 und 30 der preußischen Verfassung vom 11. Januar 1850 (wirksam seit dem 11. März 1850), die die Grundrechte der Versammlungs- und Vereinigungsfreiheit verbürgten, die Grundlagen gelegt ${ }^{39}$.

Der Wuppertaler Historiker Wolfgang E. Heinrichs beschreibt den Evangelischen Brüderverein zu Recht als Exponent und - zumindest für weite Teile des deutschen Raumes - als Vorläufer der freikirchlichen Bewegung in Deutschland ${ }^{40}$. Das liegt auch an der personellen Kontinuität dieser Erneuerungsbewegung. Wichtige Gründungspersönlichkeiten von Freikirchen waren Mitglieder des Vereins gewesen, so beispielsweise der Baptist Julius

37 Wir finden bei Grafe die moderne Fassung einer „Verzweiflung bis in die Hölle hinein“. Sie wird später durch christologische Gedanken ersetzt. Der Umschlagspunkt von der alten zur neuen Existenz liegt später nicht mehr in der Existenz selbst, sondern in Christus. Auch die Selbststudien Grafes bekommen somit eine neue Interpretation; vgl. H. Lenhard, Die Einheit der Kinder Gottes, S. 93. Im Tagebuch 6 führt Grafe aus: „Wenn Christus mein Leben geworden ist, so sind meine besten Selbststudien die: nicht über mich selbst, sondern über den Heiland nachzudenken." (Tagebucheintrag vom 16. Mai 1858)

38 Zur Gründung des Evangelischen Brüdervereins und der ersten Entwicklung siehe Hans Horn, „Der Evangelische Brüderverein. Zur Geschichte eines Missionsvereins zwischen Landeskirche und Freikirche" in: Monatshefte für Evangelische Kirchengeschichte des Rheinlandes 24 (1975), S. 211-234, W.E. Heinrichs, Freikirchen, S. 278-291; August Jung, Als die Väter noch Freunde waren. Aus der Geschichte der freikirchlichen Bewegung, Kirchengeschichtliche Monographien 5, Wuppertal-Kassel-Witten 1999; zu den Anfängen siehe: Idem, Julius Anton von Poseck. Ein Gründervater der Brüderbewegung, Wuppertal 2002, zuletzt H. Weyel, Evangelisch und frei, S. 7-9.

39 Vgl. G. Robbers, „Das Verhältnis der evangelischen Landeskirchen und Freikirchen“, S. 27-33 und W.E. Heinrichs, „Hermann Heinrich Grafe“, S. 19: „Verordnung über die Verhütung eines die gesetzliche Freiheit und Ordnung gefährdenden Missbrauchs des Versammlungs- und Vereinsrechts" (Gesetzessammlung, Nr. 277, S. 19). Das Vereins- und Versammlungsrecht vom 11. März 1850 ersetzte die Verordnung über das Versammlungs- und Vereinsrecht vom 29. Juni 1849 (Gesetzessammlung, Nr. 221), die aufgrund der oktroyierten Verfassung erlassen worden war. Vgl. W.E. Heinrichs, „Hermann Heinrich Grafe“, S. 20 und Ernst Rudolf Huber, Deutsche Verfassungsgeschichte seit 1789, Bd. 3: Bismarck und das Reich, 2., verbesserte Auflage, Stuttgart u.a. 1970, S. 109.

40 W.E. Heinrichs, „Hermann Heinrich Grafe“, S. 20. 
Köbner (1806-1884) ${ }^{41}$, der maßgebliche Begründer der „Brüderbewegung“ Carl Brockhaus (1822-1899) ${ }^{42}$ und nicht zuletzt Grafe selbst.

Bezeichnend ist die strukturelle Erneuerung, die der Verein gegenüber der Landeskirchlichen Organisationsform bot. Der Verein lehnte von Beginn an jede Unterordnung unter das kirchliche Amt ab. Exemplarisch wird diese Erneuerung an der Besetzung des ersten Vorstandes deutlich. Er setzte sich bezeichnenderweise ausschließlich aus sogenannten Laien zusammen. Darunter waren der Elberfelder Gymnasialdirektor Carl Wilhelm Bouterwek (1809-1868) ${ }^{43}$, der Landwirt Albert Schoel (Gruiten) und die Kaufleute Friedrich Wilhelm von den Steinen (Wülfrath), Carl Wilhelm Neviandt und Hermann Heinrich Grafe ${ }^{44}$.

Die Vereinsgründung lässt sich nach der Rede des Vorstands am Gründungstag als response auf die challenge der politischen Verhältnisse beschreiben. Hier wurde auf die kirchliche Lage nach der Revolution von 1848 Bezug genommen ${ }^{45}$. Der Evangelische Brüderverein stellte zunächst einen Zusammenhang von bürgerlich-konservativer und kirchlicher Ordnung her. Die tradierten Werte und Normen seien ins Wanken gekommen und die Gesellschaft aus ihren Fugen geraten. Eine Hilfe bringe nun nicht allein eine Veränderung der Verfassung, also der Form, sondern der einer solchen vorausgehenden Gesinnung. Nur die Verbreitung bestimmter evangelischer Werte werde nach Meinung der Vereinsgründer die Aufösungserscheinungen in Staat und Kirche revidieren können. Eine solche Aufgabe übersteige freilich die Möglichkeit der bisher verfassten Kirchen. Darum sei eine Zusammenfassung aller im Sinne der Erweckungsbewegung konservativ-orthodoxen Christen auf der reformatorischen Basis des sola fide nötig. Die neue Arbeit gründete anders als bei den konfessionellen Freikirchen nicht auf einer der reformatorischen Bekenntnisschriften, sondern in der aus dem Pietismus und der Erweckungsbewegung erwachsenen christozentrisch-bibelorientierten Frömmigkeit.

Wen man zu den in diesem Sinn „erweckten Christen“ zählte, ergab sich für die Vereinsgründer aus den 1846 in London formulierten neun

${ }^{41}$ Vgl. W.E. Heinrichs, Freikirchen, S. 301-326; Ruth Baresel, Julius Köbner - Sein Leben, Kassel 1930; W. E. Heinrichs, „Köbner, Julius Johannes Wilhelm“, in: Biographisch-Bibliographisches Kirchenlexikon 4, Herzberg 1992, S. 233-236.

42 Rolf-Edgar Gerlach, Carl Brockhaus - ein Leben für Gott und die Brüder, Wuppertal 1994.

43 Er war wie Grafe selbst Schwiegersohn von Karl Wilhelm Neviandt. Folgenreich war die Gründung des Bergischen Geschichtsvereins, die er zusammen mit dem Pastor D. Karl Krafft (1814-1898) in 1863 initiierte. Von 1850-1853 war Bouterwek der erste Vorsitzende.

44 Von 1854 bis 1869 hatte er den Vorsitz inne; vgl. W.E. Heinrichs, Freikirchen, S. 278.

45 Der Text bei Friedrich Koch, Der evangelische Brüderverein in Elberfeld von 1850-1900, Elberfeld 1900, S. 5-7. 
Grundsätzen der Evangelischen Allianz ${ }^{46}$. Zum Zweck der Erneuerung begann der „Evangelische Brüderverein“ systematisch sogenannte Sendboten für die Evangelisierung Deutschlands auszubilden ${ }^{47}$. Der Verein bot jedoch noch nicht die Gemeindeform, die Grafe suchte. Bei aller individuellen Evangelisation fehlte ihm die Gemeinschaft der Gemeinde, die das Herrenmahl miteinander feierte ${ }^{48}$.

\subsubsection{Die Suche nach Anschluss an Erneuerungsbewegungen}

Zur Erneuerung gehört auch die Suche nach Anschlussmöglichkeiten bei solchen Bewegungen, in denen die eigene Sicht der Erneuerung zumindest in Teilen bereits als verwirklicht angesehen wurde. Nachdem Grafe sein Amt des Diakons niedergelegt hatte, nahm er in der reformierten Gemeinde nicht länger am Abendmahl teil. Er gehörte nur noch nominell zu ihr. Es blieb die Sehnsucht wach, eine Gemeinschaft von Glaubenden, die jener in Lyon glich, zu erleben. Der ekklesiologische Grundgedanke, der Grafe in seinen Erneuerungsversuchen leitete, war der, dass es eine grundsätzliche Verschiedenheit zwischen den wirklich Glaubenden und denen, die nur dem Namen nach dazu gehörten - aber eben in Wort und Tat den evangelischen Glauben verleugneten - geben müsse. Gleichzeitig bewahrte er den Grundsatz der Einheit aller Glaubenden.

Sowohl die Brüderbewegung als auch den Baptismus empfand Grafe als zu sehr auf exklusive Sonderlehren fixiert, um für alle Erweckten Gemeinde sein zu können. An der Brüderbewegung, die sich auf die Lehre von John Nelson Darby (1800-1882) ${ }^{49}$ berief, stieß Grafe die extreme Heiligungslehre, der religiöse Absolutheitsanspruch, der alle ausschloss, die einer organisierten Ge-

46 Die neun Punkte finden sich als Beilage zu Heft Nr. 53 des Sämanns 2 (1852); die Statuten der Evangelischen Allianz bei Ruth Rouse, Stephen Charles Neill, Geschichte der Ökumenischen Bewegung 1517-1948, Bd. 1, Göttingen 1957, S. 438; lediglich die Lehre von der göttlichen Einsetzung des christlichen geistlichen Amtes und die Verpflichtung wie Dauer der Ordnung der Taufe und des Herrenmahls sind vom Verein nicht übernommen worden; siehe Erich Beyreuther, Der Weg der Evangelischen Allianz in Deutschland, Wuppertal 1969, S. 11.

47 Vgl. Andreas Heiser, „Ein Pastor - was ist das? Zur Genese unterschiedlicher Pastorenbilder und ihrer Bezugspunkte am Beispiel des Bundes Freier evangelischer Gemeinden“ in: Markus Iff, A. Heiser (Hg.), Berufen, beauftragt, gebildet - Patorales Selbstverständnis im Gespräch. Interdisziplinäre und ökumenische Perspektiven, Biblisch-Theologische Studien 131, Neukirchen-Vluyn 2012, S. 68-107.

48 Im Verein war es geboten, „alles zu vermeiden, wodurch die anerkannten Kirchengemeinschaften... in ihrem Stande bedroht werden könnten“ (Satzung des Evangelischen Brüdervereins vom 3. Juli 1850, $\$ 1$, zitiert nach H. Horn, „Der Brüderverein“, S. 232), wozu auch die gemeinsame Abendmahlsfeier gehörte.

49 Vgl. W.E. Heinrichs, Freikirchen, S. 341-376. 
meinde angehören, und die radikale Verwerfung von Amt und Organisation ab. Gerade gegen den Darbysmus verfasste Grafe später den Traktat „Der Aeltestendienst ist und bleibt eine göttliche Einsetzung für die Gemeinde "50.

Für Grafes Verhältnis zum Baptismus lagen die Dinge anders. Er erwog, sich der Baptistengemeinde, die 1852 von Julius Köbner gegründet worden war $^{51}$, anzuschließen. Grafe hielt einen solchen Anschluss für möglich, weil Köbner wie er selbst der Evangelischen Allianz aufgeschlossen gegenüberstand. Allerdings nahm die Baptistengemeinde nur solche Christen auf, welche die Glaubenstaufe an sich vollziehen lassen hatten. Grafe hingegen hielt seine Kindertaufe für bindend. Die unterschiedliche „Taufform“ bedeutete für ihn keinen unüberwindbaren Unterschied ${ }^{52}$, weil für ihn die Einheit aller Glaubenden zentral war. Es gab neben ihm etliche Christen, die die Kindertaufe als falsche Taufpraxis ablehnten, jedoch eine Gewissensnot empfanden, sich - so wie sie es wahrnahmen - wiedertaufen zu lassen.

Für Grafe aber war das Christsein primär ein individueller Akt des Gewissens. Aus der freien Gnade Gottes und der Einwilligung des Glaubenden in einer Gewissensentscheidung konstituierte sich die Einheit der Gemeinde und stellte sich im Abendmahl dar. Darum dürfe man auch dem einzelnen Gewissen zu überlassende, persönliche Erkenntnisfragen nicht über diese Einheit erheben.

\subsubsection{Das erneuerte Kirchenmodell}

Zusammen mit fünf Gleichgesinnten gründete Grafe schließlich am 22. November 1854 die erste Freie evangelische Gemeinde auf deutschem Boden in Elberfeld-Barmen. Die tragenden Motive für diese Gemeindegründung sind in dem Austrittsschreiben gebündelt, das er zusammen mit Johann Peter Wülfeling und Johann Friedrich Gottlob Paul am 30. November 1854 unterschrieb und dem Presbyterium der reformierten Gemeinde Elberfeld vorlegte $^{53}$. Hier ist ausgefürht, dass die Einheit der Gemeinde auf der Einheit der Gewissensentscheidung der Gläubigen beruht. Zudem müsse das, was eine geistliche Gemeinschaft lehre, eine Einheit mit der Überzeugung und dem Leben der Menschen bilden, die dieser Gemeinschaft angehören.

50 Elberfeld 1859 = abgedruckt bei W. Hermes, „Hermann Heinrich Grafe“, S. 383-394.

51 Zur Gründung der ersten Baptistengemeinde durch Julius Köbner, siehe W.E. Heinrichs, Freikirchen, S. 292-340; ferner Erich Geldbach, Freikirchen - Erbe, Gestalt, Wirkung, 2., völlig neu bearbeitete Auflage, Bensheimer Hefte 70, Göttingen 2005, S. 211-222.

52 Grafe ließ selbst nach der Gründung der ersten Freien evangelischen Gemeinde an seinen Kindern noch die Kindstaufe vollziehen; vgl. W.E. Heinrichs, „Hermann Heinrich Grafe“, S. 23 .

53 Text bei W. Dietrich (Hg.), Ein Act des Gewissens, S. 213-220. 
Der Gemeinde komme die Aufgabe zu, eben als Gemeinde von einer im Ganzen von Gott abgefallenen Umwelt als abgesondert und heilig darzustellen. Diese Darstellung vollziehe sich besonders in der Feier des Abendmahls. Eine Kirche, die sich als corpus permixtum konstituiere und als bloße formale Institution keine Differenz zwischen überzeugten Christen und Mitläufern mache, verleugne ihr Wesen ${ }^{54}$. Für Grafe sei die Verkündigung der Wahrheit nur dann eindeutig, wenn sich Wahrheitsanspruch und Wahrheitswirklichkeit decken.

Die neue Gemeinde orientierte sich mit ihrem Namen, dem Glaubensbekenntnis und der Verfassung an dem Vorbild der Genfer „Église évangélique libre" aus dem Jahr 184855. Dem Elberfeld-Barmer Glaubensbekenntnis war Johannes 17 vorangestellt ${ }^{56}$, um die Einheit der Christen in der Einheit von Vater und Sohn zu begründen. Das Bekenntnis beinhaltete keine „besonderen Lehrmeinungen“ und sollte „nur die unzweifelhafte Richtschnur des gesunden biblischen Glaubens" beschreiben ${ }^{57}$. Es diente der Legitimation gegenüber Kirchen und Behörden und spielte in der weiteren Geschichte der Elberfelder Gemeinde und auch des späteren Bundes keine Rolle mehr. Die Gemeinden verfuhren in ihrem Umgang mit schriftlich fixierten Glaubensbekenntnissen wie Grafe selbst, der gegen die reformatorischen Kirchen hinter die reformierten Bekenntnisse zurückging, um diese durch Rückgriff auf die Heilige Schrift zu reformieren. Wegen seines Einheitsverständnisses forderte er den Bezug auf die Schrift und nicht auf exklusive Bekenntnisse ${ }^{58}$.

In einer nach Gottes Willen geordneten Gemeinde hielt man aber „eine menschlich-organisierte Verbindung ihrer Mitglieder durch eine äußere Verfassung“ für nötig ${ }^{59}$. Diese, schon damals so bezeichnete „demokratische Verfassung“, die im Grundsatz dem kongregationalen Gemeindetypus entsprach, war

54 Ibidem, Anm. 1 und Anm. 79.

55 Wilfrid Haubeck, „Dokumentation 3: Gemeindegründung: Glaubensbekenntnis und Verfassung “ in: W. Dietrich (Hg.), Ein Act des Gewissens, S. 111-136; der Bezug Grafes auf den Genfer Bekenntnistext als Vorlage für seinen eigenen ist aus der geringeren Organisationsstufe der Berner oder Lyoner Gemeinden begründet.

56 W. Haubeck, „Dokumentation 3“, S. 123.

57 Ibidem, S. 114.

58 Grafe übersah freilich, dass Schrift und Bekenntnis auch in der reformierten Kirche seiner Zeit keine getrennten oder gar entgegengesetzten Größen darstellten, sondern mit Prävalenz der Schrift aufeinander bezogen waren. Eine Untersuchung der Bekenntnishermeneutik Grafes, der Bekenntnistexte als statisch missverstehen konnte und ihnen die Dynamik des Geistes entgegengesetzte, liegt bislang nicht vor. Grafe unterschied zwischen nützlichen Bekenntnissen, die einheitsstiftend wirkten (Apostolikum), und schädlichen Bekenntnissen, die trennend wirkten.

59 Tagebucheintrag vom 12. Februar 1853; Zitat aus einem Brief an Nathanael Benjafield Millard in Köln. 
von der Basis her aufgebaut ${ }^{60}$. Die Gemeinde hatte im Vollzug des allgemeinen Priestertums die Lehre und Personen zu beurteilen und alle wichtigen Entscheidungen zu treffen. Der Vorstand hingegen diente nur als Exekutive. So wurden die „Gemeindebeamten“ („Älteste und Diener“), die gewählt werden sollten, zwar vom Vorstand vorgeschlagen, aber „über deren Erwählung hatte dann das Vertrauen der Gemeinde" zu entscheiden ${ }^{61}$. Damit war die Einsicht realisiert worden, dass die gesamte Gemeinde als Volk Gottes anzusehen ist und im Sinn einer "geistlichen Demokratie“ die letzte Entscheidung zu treffen hat.

\subsection{Die Erneuerung nach der Gründung}

Man kann zu Recht sagen, dass es sich bei dieser Freiwilligkeitsgemeinde independent-reformierter Prägung mit starkem missionarisch-sozialem Impetus und presbyterial geordnetem Gemeindeleben um eine „moderne Kirchenform "62 handelte. Die Erneuerungsbewegung traf das Empfinden der Menschen nach religiöser Selbstbestimmung. Entsprechend breitete sich die Gemeindebewegung aus, so dass sich 1874 die „Vereinigung von freien evangelischen Gemeinden und Abendmahlsgemeinschaften“" als Bund Freier evangelischer Gemeinden etablierte ${ }^{63}$. Die folgenden Jahre lassen sich als Zeit der Institutionalisierung beschreiben. Dazu gehörte der Ausbau der verfassungsrechtlichen Grundlagen ${ }^{64}$, einheitsstiftende Bundeskonferenzen, bald eine eigene Zeitschrift und die Anstellung von Reisepredigern. Besonders durch die Gründung eigener Funktionszweige wie des Evangelisationswerks ${ }^{65}$, einer eigenen Ausbildungsstätte ${ }^{66}$, eines Verlages ${ }^{67}$, eines eigenen Diakonischen Werkes $^{68}$ und einer Missionsgesellschaft ${ }^{69}$ fand die Bewegung feste Formen.

\footnotetext{
60 Tagebucheintrag vom 2. April 1858 „Die Dienstverrichtungen in der Gemeinde“.

61 W. Dietrich (Hg.), Ein Act des Gewissens, S. 209-213.

62 W. E. Heinrichs, Freikirchen, S. 426-428.

63 H. Weyel, Evangelisch und frei, S. 38-73.

64 Statut bei R. Hoenen, Die freien evangelischen Gemeinden, S. 106f.

65 H. Weyel, Evangelisch und frei, S. 53 und W.E. Heinrichs, „Die Anfänge der InlandMission“ in: Erhard Michel et al. (Hg.), Die Inland-Mission. Geschichte, Gegenwart und Ziele. Festschrift zum 100. Geburtstag der Inland-Mission, Witten 2004, S. 8-16.
}

66 A. Heiser, „100 Jahre Theologische Hochschule Ewersbach“ in: Wilfrid Haubeck, Michael Schröder (Hg.), Lernen. Begegnen. Senden. 100 Jahre Theologische Hochschule Ewersbach, Witten 2012, S. 11-34.

67 Wilhelm Wöhrle (Hg.), Fünfzig Jahre Bundes-Verlag 1887-1937, Witten 1937; Arndt Schnepper (Hg.), 125 Jahre SCM Bundes-Verlag, Witten 2012 und H. Weyel, Evangelisch und frei, S. 58-61.

68 Ibidem, S. 61-63.

69 Ibidem, S. 63-72 und Elmar Spohn, Die Allianz-Mission und der Bund Freier evangelischer Gemeinden. Die Geschichte ihrer Beziehung und deren theologische Begründung, Geschichte 


\section{Die Freien evangelischen Gemeinden als Erneuerungsbewegung}

Wenn man die Geschichte des Anfangs der Freien evangelischen Gemeinden unter dem Aspekt der Erneuerung nacherzählt, stellt sich die Frage, was genau aus dem Ideal der Frühkirche rezipiert und nach ihrem Leitbild erneuert wurde?

Dabei ist vorab zu sagen, dass die Freien evangelischen Gemeinden sich im Verständnis des Evangeliums mit der Leuenberger Kirchengemeinschaft weitgehend eins erklärt haben ${ }^{70}$. Die eigenständigen Akzentuierungen gegenüber der reformatorischen Tradition wurden bereits im Abriss der Geschichte deutlich. Die wesentlichen Erneuerungen vollzogen sich im Verständnis der Schrift, des Glaubens, von Taufe und Abendmahl sowie der Ämterstruktur.

\subsection{Schrift}

Seit den Anfängen haben sich die Freien evangelischen Gemeinden ihren ausschließlichen Bezug auf die Heilige Schrift bewahrt. Wenngleich sie auf dem Boden des Apostolischen Glaubensbekenntnisses stehen, betonen sie ausdrücklich, dass die Bibel als Wort Gottes und als Heilige Schrift alten und neuen Testaments verbindliche Grundlage für Glauben, Lehre und Leben ist $^{71}$. Bekenntnisse verstehen sie in erster Linie als Lebensausdruck des Glaubens. Aus diesen Gründen sind im Bund Freier evangelischer Gemeinden keine eigenen für alle Gemeinden gültigen Glaubensbekenntnisse formuliert worden. Freilich erkennen Freie evangelische Gemeinden, dass in der Heiligen Schrift das Bekenntnis zu Jahwe, dem Gott Israels und dem Vater Jesu Christi sowie das Bekenntnis zu Jesus Christus als den Sohn Gottes und Retter der Welt, in Wort und Tat konstitutiv für den christlichen Glauben sind ${ }^{72}$.

und Theologie der Freien evangelischen Gemeinden 6.1, Witten 2011 sowie Erhard Michel, Johannes Reimer et al. (Hg.), Theologische Beiträge zur Mission und Gemeindegründung im Umfeld von Allianz-Mission und Freien evangelischen Gemeinden. Festschrift zum 125-jährigen Jubiläum der Allianz-Mission, Wuppertal 2014.

70 „Wir bekräftigen die Aussage über das Evangelium in der Konkordie reformatorischer Kirchen in Europa und stimmen mit dem in der Leuenberger Konkordie (LK 6-13) umrissenen gemeinsamen Verständnis des Evangeliums überein. "Zum Verständnis des Evangeliums, FeG-Text Dezember 2009, Witten 2009, S. 3.

71 Verfassung des Bundes Freier evangelischer Gemeinden in Deutschland KdöR, Witten 1995, Sonderdruck, S. 1; so ist bereits in dem Statut für die Ortsgemeinde von 1877 festgelegt, dass sie sich aus solchen Personen zusammensetzt, „die es anerkennen, dass wie das Wort Gottes für den einzelnen Gläubigen Regel und Richtschnur sein soll, so auch seine Anweisungen für die Bildung und Leitung des christlichen Gemeinschaftslebens allein bestimmend und bindend sind." „Statut von 1877" in: R. Hoenen, Die freien evangelischen Gemeinden, S. 106. 72 Vgl. Röm 10,9f.; 1Kor 15,1-5; Vgl. Zum Verständnis des Evangeliums, S. 2. 
Der ständige, meist unmittelbare Rückbezug auf die Schrift bedarf der Schriftauslegung nach nachvollziehbaren Kriterien. Auch in Freien evangelischen Gemeinden soll das Prinzip der Auslegung sein, „was Christum treibet "73, das heißt was den geschichtlichen und erhöhten Christus als „Mitte der Schrift" begreift ${ }^{74}$ und durch den Heiligen Geist als gestaltende Kraft in die Mitte des persönlichen, des gemeindlichen und auch des gesellschaftlichen Lebens stellt. Alle anderen Glaubensinhalte sind der in Jesus Christus wirksamen gnädigen Zuwendung Gottes zum Sünder zu- bzw. unterzuordnen, so dass in zweitrangigen Fragen unterschiedliche Erkenntnisse möglich sind. Das dispensiert die Freien evangelischen Gemeinden nicht davon, sich im Hören auf die Heilige Schrift um ein Verständnis zu bemühen, wo die Grenze zwischen erst- und zweitrangig verläuft. Wenn es auch in Zukunft in Freien evangelischen Gemeinden zu christlicher und nicht beliebiger Erneuerung kommen soll, wird die Auslegungsgemeinschaft darauf angewiesen sein, sich „bei den biblischen Überlieferungen an den Kriterien Christusgemäßheit, Schriftgemäßheit und Zeitgemäßheit " ${ }^{\text {"75 }}$ zu orientieren.

\subsection{Glaube}

Für Freie evangelische Gemeinden ist Gottes Wort die Ermöglichungsbedingung für allen menschlichen Glauben. Gottes Wort kommt erst dort zum Ziel, wo es menschlichen Glauben weckt und im Gehorsam des Glaubens angenommen wird.

Freilich ist es nach frei-evangelischem Verständnis der Geist, der den Glauben weckt. Der Mensch erkennt den gekreuzigten und auferstandenen Jesus Christus als persönlichen Herrn und Heiland an. Der Glaube ist demnach die dankbare Antwort auf das Evangelium. Das Geschenk der Gnade Gottes bleibt dabei für den Menschen unverfügbar (vgl. Eph 2,8f.). Man kann den Freien evangelischen Gemeinden darum nicht anlasten, sie räumten einem menschlichen Element zu großes Gewicht ein, indem sie den Glauben als Bedingung der Gemeindezugehörigkeit verstünden.

Der Glaube wird vielmehr als die Existenzweise der neuen Kreatur verstanden. Es gibt ihn nicht als dauerhaftes, starkes Gottvertrauen ${ }^{76}$, sondern

\footnotetext{
73 Vgl. Oswald Bayer, Martin Luthers Theologie, Tübingen ${ }^{3} 2007$, S. 73-75.

$74 \mathrm{Vgl}$. Zum Verständnis des Evangeliums, II. Zum Verständnis des Evangeliums, 1. Grundsätze, 1.5 .

75 Markus Iff, „Was sind Freie evangelische Gemeinden? Systematisch-theologische Grundzüge zum Selbstverständnis“ in: Wilfrid Haubeck, Wolfgang Heinrichs (Hg.), Gemeinde der Zukunft - Zukunft der Gemeinde. Aktuelle Herausforderungen der Ekklesiologie, Theologische Impulse 22, Witten 2011, S. 162.
}

76 Vgl. J. Demandt, „Christliche Lehre“, S. 42. 
nur im Modus eines Wechselspiels von „Gottvertrauen, eigenmächtigem Handeln, Bitte um Vergebung der Schuld und erneutem Vertrauen auf Gottes gnädige Zuwendung, das die Existenz der Glaubenden ausmacht und ihn mit seinen Brüdern und Schwestern verbindet" ${ }^{\text {"777 }}$.

Weil der geistgeweckte Glaube die neue Existenzweise der Gemeinde ist, wird er nach frei-evangelischem Verständnis zu den äußeren Kennzeichen der Kirche gezählt ${ }^{78}$. In der 2009 verabschiedeten Erklärung „Zum Evangeliumsverständnis“ heißt es darum: „Aus dem Wesen der Gemeinde als Gemeinschaft der Glaubenden ergeben sich für Freie evangelische Gemeinden als äußere Kennzeichen (notae externae) der Gemeinde im Anschluss und im Unterschied zur Confessio Augustana (CA VII) die unverfälschte Verkündigung des Evangeliums und der durch Wort und Tat bezeugte Glaube. Von Gemeinde Jesu Christi ist da zu sprechen, wo Gottes Wort verkündigt, geglaubt und in der Gemeinschaft der Heiligen gelebt wird. "79

Dass die Freien evangelischen Gemeinden damit nicht nur Grundsätze des Neuen Testaments anwenden, sondern auch die auf sie bezogene Tradition erneuern, zeigt, dass bereits die Apologie des Augsburger Bekenntnisses ${ }^{80}$ und auch die reformierten Bekenntnisschriften die Antwort des Menschen zu den notae rechneten ${ }^{81}$. Konstitutiv ist der Glaube für die Gemeinde, insofern er nicht der Einzige, aber ein mit zu Stande bringender Faktor ist ${ }^{82}$. Der Glaube wird als lebendig verstanden. Darum bedarf er geistlicher Impulse

77 Ibidem, S. 42.

78 Vgl. Idem, „Kirchen in Gemeinschaft? - Wachsende Gemeinschaft aller Glaubenden! Anmerkungen aus dem Bund Freier evangelischer Gemeinden zu einer ökumenischen Studie zu Fragen der Ekklesiologie“ in: Theologisches Gespräch 19 (1995), S. 15-23.

79 Zum Verständnis des Evangeliums, II. Zum Verständnis des Evangeliums, 3. Eigenständige Positionen und Akzentuierungen 3.2, S. 6. Dass es sich dabei durchaus um bis in das antike Christentum zurückreichende Auffassungen handelt, zeigt etwa der Anonymus, Expositio super symbolum 13 (Liuwe H. Westra, The Apostles 'Creed. Origin, history, and some early commentaries, Instrumenta patristica et mediaevalia 43, Turnhout 2002, S. 507), wo es heißt: „Ibi est ecclesia catholica ubi est congregatio fidelium qui rectam fidem credunt et tenent et in opere bono perficiunt."

80 „Darum sagen und schließen wir nach der heiligen Schrift, dass die rechte christliche Kirche sei der Haufe hin und wieder in der Welt derjenigen, die da wahrlich gläuben dem Evangelio Christi und den heiligen Geist haben." (Apologie CA VII,28, S. 240,47-51).

81 Heinrich Bullinger, Das zweite Helvetische Bekenntnis von 1566, Kapitel 17; vgl. Eberhard Busch, Reformiert. Profil einer Konfession, Zürich 2007, S. 153.

82 Darin stimmen die Freien evangelischen Gemeinden mit den Schwesterkirchen der Vereinigung Evangelischer Freikirchen überein; vgl. Vereinigung Evangelischer Freikirchen (Hg.), Freikirchenhandbuch. Informationen-Anschriften-Texte-Berichte, Ausgabe 2004, Wuppertal, 2004, S. 141. 
wie den Gottesdienst, das Gebet, die Schriftlektüre und auch weitere Formen geistlicher Gemeinschaft.

\subsection{Taufe und Abendmahl}

Aufgrund der Prävalenz des Glaubens erneuern Freie evangelische Gemeinden ihr Verständnis von Taufe und Abendmahl. Sie gehen davon aus, dass die Taufe im Glauben wirksam ist, und der lebendige Gott bezeugt, dass er die Glaubenden als seine Kinder angenommen hat, ihnen die Gabe des Heiligen Geistes verliehen hat und sie zu einem Leben im Dienst an den Mitmenschen und der Welt beruft ${ }^{83}$. Im Rückgriff auf die Taufformen, die in der Missionssituation der ersten im Neuen Testament dargestellten und $\mathrm{zu}$ Wort kommenden Gemeinden beschrieben ist, betonen die Freien evangelischen Gemeinden, dass die Taufe nur aufgrund des persönlichen Glaubens vollzogen werden kann, der durch die Verkündigung des Evangeliums und das Wirken des Geistes Gottes geweckt wird und zugleich dankbare und gehorsame Antwort des Menschen ist. Eine Taufhandlung ohne den persönlichen Glauben des Täuflings wird daher nicht als Taufe verstanden. Darum wird eine spätere Taufe aufgrund des Glaubens auch nicht als Wiedertaufe aufgefasst. Aus der Auseinandersetzung zwischen Hermann Heinrich Grafe und Julius Köbner ${ }^{84}$ ging diese Haltung bezüglich der Säuglingstaufe, die in Freien evangelischen Gemeinden bis heute vorherrscht, hervor. Wenn jemand die Säuglingstaufe empfangen hat und aufgrund einer vor Gott gewonnen Überzeugung im Gewissen darin seine gültige Taufe sieht, wird diese Überzeugung geachtet, und er kann dann ohne „Glaubenstaufe“ Mitglied einer Freien evangelischen Gemeinde sein.

Auch bezüglich des Abendmahls hat Hermann Heinrich Grafe die evangelische Tradition, dass der Glaube das Mahl zum Heil empfängt, der Unglaube aber zum Gericht, lediglich gegenüber einer Praxis des unterschiedslosen Austeilens des Mahls erneuert ${ }^{85}$. Das Abendmahl ist einsetzungsgemäß den Glaubenden vorbehalten. In ihm schenkt sich der auferstandene Herr Jesus Christus in seinem für alle dahingegebenen Leib und Blut durch sein verheißenes Wort mit Brot und Wein der Gemeinschaft der Glaubenden. Er lässt die Glaubenden erfahren, dass sie Glieder am Leib Jesu Christi sind. Entspre-

83 Zum Verständnis des Evangeliums, S. 6; vgl. J. Demandt, „Christliche Lehre“, S. 44.

${ }^{84}$ Vgl. W.E. Heinrichs, Freikirchen, S. 301-326; R. Baresel, Julius Köbner; W.E. Heinrichs, „Köbner, Julius“, S. 233-236.

${ }^{85}$ Siehe oben S. 21; zu den heutigen Positionen siehe: J. Demandt, "Christliche Lehre“, S. 45. und Zum Verständnis des Evangeliums, II. Zum Verständnis des Evangeliums, 3. Eigenständige Positionen und Akzentuierungen 3.5, S. 6. 
chend haben sich die ersten Freien evangelischen Gemeinden in Deutschland zunächst als „Abendmahlsgemeinschaften“ konstituiert.

\section{4. Ämter}

Die Erneuerung der Ämter in Freien evangelischen Gemeinden wird deutlich auf dem Hintergrund der pietistischen und erwecklichen Tradition. Das Gemeindeleben ist von dem in der Reformationszeit wiederentdeckten „allgemeinen Priestertum der Gläubigen“ geprägt ${ }^{86}$. Aus dessen soteriologischer Implikation, dass jeder Mensch durch Christus Zugang zu Gott hat, folgt die ekklesiologische, dass ein Weihesakrament für ein herausgehobenes Priestertum und eine hierarchische Struktur in den Gemeinden als nicht schriftgemäß aufgefasst wird. Vielmehr werden die Ämter funktional verstanden und bestimmten Menschen „berufungs-, gaben- und ausbildungsorientiert von der Gesamtgemeinde für eine begrenzte Zeit anvertraut " ${ }^{87}$. So ist von Beginn an eine klare Leitungsstruktur eingeschlossen. Grafe selbst leitete alle Dienstämter in den Gemeinden von dem einen Ältestenamt ab. Er differenzierte nicht zwischen Ältesten, Bischöfen und Pastoren. Die Begriffe seien nur unterschiedliche Bezeichnungen für ein- und dasselbe „Dienstamt “" ${ }^{\text {“8 }}$. Für Grafe kulminierten alle Dienste und Ämter, von denen das Neue Testament handelt, in dem Ältestenamt. In einer „evangelisch geordneten Gemeinde“ seien Älteste (Presbyter) zu berufen. Sie nehmen je nach Begabung durch den Heiligen Geist die Funktion eines Bischofs, Hirten (Pastors), Lehrers oder Vorstehers wahr ${ }^{89}$. Aber dieses Amt begründete keinen Unterschied zwischen

${ }^{86}$ Vgl. Klaus Peter Voss, Der Gedanke des allgemeinen Priester- und Prophetentums. Seine gemeindetheologische Aktualisierung in der Reformationszeit, Wuppertal 1990.

87 M. Iff, „Was sind Freie evangelische Gemeinden“, S. 161.

88 Tagebucheintrag vom 2. April 1858 in: W. Haubeck et al. (Hg.), Lebenszeichen, S. 198205; Grafe spricht von „Dienstverrichtungen“, zu denen auch „besondere Dienste“ (S. 198) wie der des Pastors zählen; mit profunder exegetischer Begründung vertreten von Wilfrid Haubeck, Zum Verständnis von Ältesten und Pastoren, in: Wilfrid Haubeck et al. (Hg.), Die Leitung der Gemeinde. Das Miteinander von Pastoren und Ältesten, Theologische Impulse 5, Witten 2002, S. 9-26.

89 Tagebucheintrag vom 2. April 1858 in: W. Haubeck et al. (Hg.), Lebenszeichen, S. 203; H. Weyel, Zukunft braucht Herkunft, S. 164; in Grafes programmatischem Titel von 1859 heißt es: „Nirgendwo im Neuen Testament finden wir auch nur eine Andeutung davon, dass in Folge des früheren oder späteren ,Abfalls' die Ämter in den Gemeinen in Frage gestellt werden" in: H.H. Grafe, Der Ältestendienst ist und bleibt eine göttliche Einsetzung für die Gemeinde, Elberfeld 1859, S. 27, W. Hermes, Grafe, S. 393. Weder falsche kirchliche Ordnungen noch die Auflösung jeder Ämterordnung seien vom Neuen Testament her begründet: Grafe forderte einen evangelischen Gebrauch der Ämter. Dieser bestehe darin, die Gaben des Geistes nicht von den Ämtern und die Ämter nicht von den Gaben des Geistes zu trennen; ausgezeichnet dargestellt bei H. Lenhard, Die Einheit der Kinder Gottes, S. 122-124. 
Geistlichen und Laien ${ }^{90}$. Freilich entfaltete Grafe seine Amtsvorstellung in Abgrenzung zu einem katholischen und einem evangelischen Amtsverständnis. Sowohl die römisch-katholische Kirche, in der das Amt von der Person getrennt sei, als auch die evangelischen Kirchen, in denen die „Verleihung des kirchlichen Amtes ... nur eine rein menschliche Ceremonie " ${ }^{91}$ sei, verwirklichten nicht umfänglich die neutestamentliche Wahrheit. Diese bestünde darin, dass der Geist „zu den Dienstverrichtungen am Leibe Christi die verschiedenen Glieder desselben verschiedenartig ausrüstet und ihr Werk durch seinen Segen autorisiert " ${ }^{\text {"92 }}$. Die Verleihung der Gaben ist demgemäß eine göttliche Ordnung, die bei Grafe vorrangig auf die Gemeinde als den unsichtbaren Leib Christi bezogen war. Dieser Leib sollte durch die verschiedenen Dienste erbaut werden, indem die Gläubigen in der sichtbaren Gemeinde „in organischer Gliederung sich einander Handreichung tun "93. Die sichtbare Gemeinde vollzieht somit nur eine Handlung Gottes nach. Die enge Beziehung der sichtbaren auf die unsichtbare Gemeinde trat im Amtsverständnis Grafes klar zu Tage.

Dass auf dem Hintergrund dieses Amtsverständnisses Erneuerung möglich ist, zeigt sich daran, dass beispielsweise dem Dienst von Frauen als Pastorinnen im Deutschen Bund in 2010 mehrheitlich zugestimmt wurde ${ }^{94}$.

\section{3. Ökumenische Chancen}

Da die Freien evangelischen Gemeinden keine Sonderlehren vertreten, ergeben sich aus der gemeinsamen Abhängigkeit von Jesus Christus große Gemeinsamkeiten in der Lehre mit anderen Kirchen. Diese Gemeinsamkeiten sind unter den in der Vereinigung evangelischer Freikirchen vertretenen Kirchen besonders ausgeprägt ${ }^{95}$.

Die Freien evangelischen Gemeinden sind mit einem Glaubensbekenntnis in die Geschichte gestartet, welches das ökumenische Wort aus Johannes 17,21 voranstellte. Ihren Gründern war bewusst, dass auch eine protestantische Partikularkirche weiterhin das Ziel verfolgen muss, durch Gebet,

\footnotetext{
90 Tagebucheintrag vom 2. April 1858 in: W. Haubeck et al. (Hg.), Lebenszeichen, S. 203, bietet einen grundlegenden Abschnitt zu „Die Dienstverrichtungen in der Gemeine“.

91 Tagebucheintrag vom 8. Februar 1852 in: W. Haubeck et al. (Hg.), Lebenszeichen, S. 63; vgl. H. Lenhard, Die Einheit der, S. 123.

92 Tagebucheintrag vom 8. Februar 1852 in: W. Haubeck et al. (Hg.), Lebenszeichen, S. 61; vgl. H. Lenhard, Die Einheit der, S. 123.

93 Tagebucheintrag vom 2. April 1853 in: H. Lenhard, Die Einheit der Kinder Gottes, S. 123.

94 Vgl. J. Demandt, „Christliche Lehre“, S. 48.

95 Vgl. Ibidem, S. 36.
} 
persönliche Begegnungen, gemeinsamen Dienst und ernsthafte theologische Gespräche konfessionelle Egoismen abzubauen und die in Christus bereits bestehende Einheit erkennbar zu machen, „damit die Welt glaube“. Dieses Ziel bleibt bestehen, auch wenn das zahlenmäßige Wachstum und die konfessionelle Zersplitterung der einen Kirche Jesu Christi im Lauf der letzten beiden Jahrhunderte die sichtbare Darstellung ihrer Einheit unmöglich erscheinen lässt.

Das Streben nach geistlicher Einheit beginnt freilich innerhalb der eigenen Denomination. Deshalb darf der Bund Freier evangelischer Gemeinden nicht lediglich als ein Zweckverband zur Erledigung übergemeindlicher Aufgaben gesehen werden. Er ist vielmehr eine legitime Gestalt des Leibes Christi neben anderen ${ }^{96}$. Der Bund versteht sich als eine „geistliche Lebensund Dienstgemeinschaft “97 selbständiger Ortsgemeinden. Nun ist aber die „Erbauung der Gemeinde“ dazu angetan, „die Grenze der einzelnen Ortsgemeinde“ zu überschreiten ${ }^{98}$. Auch wenn der Bund Freier evangelischer Gemeinden seit 1874 aus selbständigen Ortsgemeinden besteht, kann nicht von völliger Unabhängigkeit gesprochen werden. Es besteht eine wesensmäßige Verbundenheit untereinander. Wollte man auf völlige Unabhängigkeit bestehen, gerieten die Gemeinden gleichermaßen mit ihrer Zugehörigkeit zum Gemeindebund wie auch zur weltweiten Christusgemeinde in einen Selbstwiderspruch ${ }^{99}$.

Darum versuchen die Freien evangelischen Gemeinden, dem Ziel der Einheit durch die Vernetzung in nationalen Bünden sowie dem Internationalen Bund Freier evangelischer Gemeinden und der Mitarbeit in der Arbeitsgemeinschaft Christlicher Kirchen in Deutschland näher zu kommen. Harding Meyer hat das Ziel der ökumenischen Arbeit darin gesehen, „die Gemeinschaft aller, die an Christus glauben, ,die Einheit der Christen “" 100 zu fördern. Da auch Freie evangelische Gemeinden sich nicht mit der Konstatierung der Einheit der Christen in der unsichtbaren Kirche zufriedengeben ${ }^{101}$, versuchen

96 J. Demandt, „Christliche Lehre“, S. 50.

97 Verfassung des Bundes Freier evangelischer Gemeinden KdöR, Präambel, S. 1.

98 W. Haubeck, „Zum Verständnis der Gemeinde bei Paulus“ in: Idem/Wolfgang Heinrichs, Gemeinde der Zukunft, S. 7-38.

99 Vgl. J. Demandt, „Christliche Lehre“, S. 51.

100 Harding Meyer, Ökumenische Zielvorstellungen, Bensheimer Hefte 78, Göttingen 1996, S. 13.

101 Begrifflich geht die Unterscheidung von „sichtbarer“ und „unsichtbarer Kirche“ (ecclesia visiblisia und ecclesia invisibilis) vermutlich auf Zwingli zurück. Zwingli, Fidei expositio, 1531; siehe auch: Albrecht Ritschl, „Ueber die Begriffe: sichtbare und unsichtbare Kirche [1859]“ in: Idem, Gesammelte Aufsätze, Freiburg-Leipzig 1893, S. 68; vgl. Wilfried Härle, „Kirche 
sie, die sichtbare Gemeinschaft der Glaubenden zu fördern ${ }^{102}$. Den persönlichen Glaube an Jesus Christus, den Gehorsam gegenüber dem Wort und Willen Gottes, sehen sie dabei als Voraussetzung für die Gemeindemitgliedschaft an. Dieses Selbstverständnis ist offen für ökumenische Partnerschaft, weil es für die Gemeinschaft keine unbiblischen Hürden errichtet. Darum hat der Bund Freier evangelischer Gemeinden bereits in der Vergangenheit mit anderen Kirchen zusammengearbeitet, wo es um gemeinsame Anliegen ging. Dies kann in Zukunft intensiver betrieben werden. Im ökumenischen Gespräch erweisen sich die Gemeinsamkeiten im Vergleich zu den Unterschieden häufig als bedeutsamer.

Gerade in internationaler Perspektive lassen sich in den letzten Jahrzehnten stärker gemeinsame Interessen zwischen dem Ökumenischen Rat der Kirchen und der World Evangelical Alliance, in der etliche Freie evangelische Bünde vertreten sind, wahrnehmen. Ein großer Schritt in dieser Richtung ist zuletzt durch das Dokument „Das christliche Zeugnis in einer multireligiösen Welt“, das am 28. Juni 2011 von einer gemeinsamen Kommission des Päpstlichen Rats für Interreligiösen Dialog, des Ökumenischen Rats der Kirchen und der World Evangelical Alliance veröffentlicht worden ist, getan worden ${ }^{103}$.

\section{Schluss}

Kirchliche Erneuerung geschieht niemals monokausal und nur selten nach durchgeformten Programmen und Strategien ${ }^{104}$. Am Beispiel der Entstehung der Freien evangelischen Gemeinden zeigt sich ein Zusammenspiel von äußeren und inneren Kausalitäten. Aus der Außenperspektive betreffen die kulturellen und gesellschaftlichen Veränderungen wie auch die Wand-

VII. Dogmatisch“ in: Theologische Realenzyklopädie 18, Berlin-New York 1989, S. 286. Solche Rede von den beiden Kirchen leistet dem Missverständnis Vorschub, als sei die wahre Kirche eine als bloße Idee existierende Gemeinschaft. Dagegen führte bereits Melanchthon ausdrücklich an: Hans Engelland (Hg.), Melanchthons Werke 2/2, Gütersloh 1953, S. 474, die Kirche sei keine Platonica civitas (CA VII, 20 Apologie, Bekenntnisschriften, S. 238,1722. Luther selbst sprach daher lieber von der ecclesia abscondita, M. Luther, De servo arbitrio, 1525, WA 18,652,23, indem er bedachte, dass die Kirche zwar als Glaubensgemeinschaft unsichtbar sei, dass aber freilich an äußeren Zeichen erkennbar wäre, wo die Kirche in der Welt zu finden sei.

102 Vgl. Vereinigung Evangelischer Freikirchen (Hg.), Freikirchenhandbuch, S. 32.

103 http://www.oikoumene.org/de/resources/documents/programmes/interreligious-dialogue -and-cooperation/christian-identity-in-pluralistic-societies/christian-witness-in-a-multi-religious-world, abgerufen am: 30.12.2014.

104 Solche Programme finden sich nicht erst, aber vor allem seit den 60er Jahren des 20. Jahrhunderts; vgl. R. Schloz, „Kirchenreform“, S. 51-58. 
lung der politischen Kontexte immer auch die Kirche und ihre Anpassung an äußere Verhältnisse und Strukturen in einer gewandelten Umwelt. Aus der Innenperspektive führen neue theologische Einsichten, Erkenntnisse und geistliche Erfahrungen zu aktiven Maßnahmen der Erneuerung. Wie die Reformation im 16. Jahrhundert eine theologische Umbesinnung und Überzeugung bedeutete, in deren Folge die Relation von Glaube und Heil zur Kirche und zur kirchlichen Organisation neu bestimmt wurde, so führten die Freien evangelischen Gemeinden wesentliche Einsichten von Glaube und individueller Verantwortung des Menschen zu einer eigenständigen evangelischen Gemeindeform. In dem hohen Maß der Partizipation der Gemeindemitglieder wurde sie Vorbild für Reformen, die in der späten Mitte des letzten Jahrhunderts als „Demokratisierung“ in evangelischen Landeskirchen umgesetzt wurden ${ }^{105}$. Zukünftig wird ihre Aufgabe darin bestehen, als inzwischen institutionalisierte Gemeinden nicht wehmütig auf die Flexibilität des Anfangs zu schauen, sondern die erneuernde Kraft des Geistes in ihrer eigenen Bewegung zu kanalisieren, da sich von den Rändern der Freikirchenbewegung bereits neue freikirchliche Bewegungen zu lösen beginnen ${ }^{106}$.

105 Vgl. M. Honecker, Evangelisches Kirchenrecht, S. 293.

$106 \mathrm{Vgl}$. Verein für Freikirchenforschung (Hg.), „Frei - freier - am freisten“? Unabhängige Gemeinden in Deutschland und ihr Verhältnis zu den (Frei-)Kirchen, in: Freikirchenforschung 22, Münster 2013, S. 12-109; die kongregationalistische Kirchenform der Freien evangelischen Gemeinden orientiert sich nicht an der geschichtlich gewordenen kirchlichen Gestalt, sondern sucht als Kirche im Prozess nach der je aktuellen kontextuellen Verwirklichung von Kirche; vgl. die baptistische Parallele bei Andrea Strübind, „Die «Kirche der Freien». Der Kongregationalismus als Kirchenmodell. 400 Jahre Baptismus" in: Materialdienst des Konfessionskundlichen Instituts 60 (2009), S. 103-109. Der Amsterdamer Kirchenhistoriker Markus Matthias beschrieb diese Problematik als dem Pietismus immanent. Der Pietismus werde zu „einer utopischen, prinzipiell nie zum Ziel kommenden Bewegung, zum einen weil er eine universale und dauerhafte Reform über die Veränderung (Bekehrung und Wiedergeburt) von Individuen erreichen will, zum anderen weil jeder erreichte Christianisierungsgrad wieder Anlass für ein neues ,entschiedeneres' Christentum werden kann und zum Zwecke christlicher Identitätsbildung werden muss“, Markus Matthias, „Bekehrung und Wiedergeburt“ in: Hartmut Lehmann (Hg.), Geschichte des Pietismus, Bd. 4: Glaubenswelt und Lebenswelten, Göttingen 2004, S. 50. 